\title{
DOCUMENTOS
}

\section{ACERVO DA CASA DE OSWALDO CRUZ}

\author{
HOLDINGS OF CASA DE OSWALDO CRUZ
}

No início, a vontade. A partir de outras investigações e descobertas, delimita-se um sítio virtual. Sondagens, prospecções e, de repente, um indício. Demarca-se o terreno. Cuidadosamente são retiradas as camadas de um tempo geológico, da sua maneira peculiar de produzir sombras sobre o passado. Aos poucos, muitas vezes em meio a um sentimento de surpresa, formas são literalmente trazidas de novo à luz e retornam a um tempo humano, histórico. De um lado, renascem os monumentos e sua vocação para a eternidade. De outro, simples vestígios de um cotidiano, efêmero pela sua singularidade, são elevados àquela condição. São monumentalizados. Um novo manancial de informações torna-se acessível.

A analogia entre a arqueologia, de um lado, e a arquivologia e a documentação, de outro, é atraente. Quando tratamos de sociedades ou mesmo de campos de atividade humana com pouca tradição arquivística ou historiográfica, a ausência de rotinas estabelecidas para o trato de massas documentais terminam por expô-las a toda sorte de fatores de destruição, de 'soterramento', culminando por estender amplas zonas de sombra sobre o passado. Podem assim, de uma certa forma, tornar remoto um acontecimento da véspera.

Nestas situações, o trabalho arquivístico voltado para os registros do passado quando enfim se manifesta uma vontade pela sua realização - tem muito de uma arqueologia documental contemporânea e é marcado pela idéia de resgate. Mais do que nunca, realiza-se em estreita relação e muitas vezes de forma simultânea ao processamento de fontes e informações próprio da produção do conhecimento histórico.

Muito há que ser feito no que se refere à reunião, ao tratamento e ao referenciamento dos materiais ainda passíveis de serem resgatados, e ao estabelecimento de práticas arquivísticas capazes de projetar uma memória futura a partir dos documentos que são hoje produzidos. Igualmente importante é a tarefa de trazer a público as potencialidades que se manifestam na medida em que este trabalho se realiza. Conter o soterramento, trazer à luz o que pode iluminar, impedindo que o silêncio seja a mais importante informação disponível: com certeza estes são caminhos de afirmação de uma vontade que aos poucos se institucionaliza.

O documento 'Relatório anual do inspetor sanitário dr. B. Penna' - cujos trechos mais importantes são transcritos literalmente a seguir — descreve os serviços executados pelo médico em 1904. Nele encontramos as impressões de Penna a respeito de uma conjuntura importante: a Revolta da Vacina. Estabelece, portanto, um diálogo frutífero com estudos recentes dedicado à história da saúde pública no Brasil. 


\section{NO PEQUENINO NINGUÉM TOCA!}

Belisário Augusto de Oliveira Penna nasceu em Barbacena (MG) em 29 de novembro de 1868, filho do barão e visconde de Carandaí. Entrou na Direção Geral de Saúde Pública em 1904 como inspetor sanitário, participando de diversas campanhas, entre elas, o combate ao impaludismo no prolongamento da Estrada de Ferro Central do Brasil junto com Carlos Chagas (1907-10). Em 1912, com Arthur Neiva, do Instituto Oswaldo Cruz, percorreu regiões do Piauí, Pernambuco, Bahia e Goiás. Trabalhou também na profilaxia rural nos subúrbios da Leopoldina Railway (1914-19).

Com a ascensão de Carlos Chagas à direção do Departamento Nacional de Saúde Pública (DNSP), em 1920, foi nomeado chefe da Diretoria de Profilaxia Rural. No governo de Artur Bernardes, esteve preso durante um ano por ter apoiado publicamente o movimento tenentista de 1924. Em 1930, aderiu à revolução e foi nomeado diretor do DNSP pelo governo provisório de Getúlio Vargas. Filiou-se, em 1932, à Ação Integralista Brasileira (AIB) fundada por Plínio Salgado, tornando-se membro da Câmara dos 40, órgão supremo do integralismo. Faleceu a 4 de novembro de 1939, no Rio de Janeiro.

O relatório do inspetor sanitário Belisário Penna apresenta informações a respeito do modo 'persuasivo' de cumprir as rigorosas regulamentações do código sanitário da época. Seu maior interesse talvez resida na descrição de um modus vivendi no mesmo momento, no mesmo lugar e em torno das mesmas questões que puseram o Rio de Janeiro em polvorosa: fala de sua bem-sucedida atuação como sanitarista em zona limítrofe ao Centro da cidade, no período da chamada Revolta da Vacina.

Seu pretexto foi a publicação do decreto de regulamentação de obrigatoriedade. Uma revolta popular contra a regulamentação da lei que tornava a vacinação antivariólica obrigatória. No entanto, apesar de parte do período de que trata o relatório ter coincidido com o estado de sítio, não há nenhum comentário específico a respeito dos fatos. Mas como são feitas observações sobre as condições de vida da população e sobre o projeto de obrigatoriedade da vacina, o silêncio é revelador.

Nomeado inspetor sanitário no Rio de Janeiro a 5 de maio de 1904, Penna iniciou sua

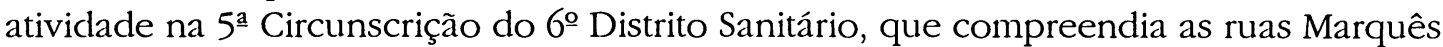
de Sapucaí, Santana, General Pedra, Senador Eusébio, Visconde de Itaúna, São Leopoldo, Alcântara e Marquês de Pombal, área de pequeno comércio e inúmeras estalagens, casas de cômodos, cortiços.

O relatório foi apresentado em 8 de janeiro de 1905 e compreende os serviços realizados no período de 17 de maio a 31 de dezembro de 1904. Dedicando-se à vigilância médica e à vacinação, a princípio Belisário Penna encontrou relutância da população, mas, segundo biografia escrita por João Fernandes Penna, logo foi vencida "graças ao seu jeito especial de lidar com o povo". Os resultados obtidos, na verdade, deveram-se à ameaça de recolher os habitantes aos hospitais, conseguindo assim vaciná-los. "Chegou a ser ameaçado pelos mais recalcitrantes, o que não chegou a acontecer, em parte por um fato, comentado na época, que foi a interferência do maior valentão daquela zona, o temível 'Estica da Agonia' (sic) , que sentenciou: 'No pequenino ninguém toca!'” 
"Relatorio dos serviços executados pelo inspector sanitário dr. Belisário Penna no decurso de maio a dezembro de 1904.

Cumprindo o disposto no $n^{\circ} X V I I$ do art. 23 do regulamento sanitário escrevo o presente relatorio dos serviços a meu cargo como inspector sanitário.

Pelo regulamento actual é ardua e fatigante a missão do inspector sanitário, forçado a ter sempre presa a sua attenção às multiplas attribuições que lhe cabem; a desenvolver

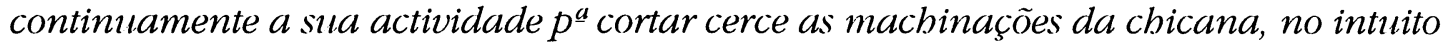
de burlar as suas determinaçōes; a attender a mil detalbes de serviço e a empregar tactica e habilidade para educar e convencer esse povo obliterado de abusões e principios falsos, albeio inteiramente aos mais comezinbos preceitos da bygiene, que, parece-me, não tinha sido até então applicada com seriedade e com animo firme de ver realizados e cumpridos os seus preceitos.

A elle, pois, que é quem está em contacto directo e imediato com a população; quem executa o regulamento; quem applica penas; quem attende em primeiro lugar ás reclamações, cabe a maior responsabilidade na execução da lei, que é benefica em seus effeitos, mas dura na applicação. ...

Dediquei-me, pois, exclusivamente aos serviços de vigilancia medica e vaccinações durante os meses de junbo e julbo, e o resultado não se fez esperar.

A principio encontrei reluctancia por parte da população ignorante, que acreditava ser a vaccina, em tempo de epidemia, não um preservativo, mas um propagador da asquerosa molestia.

Felizmente, com calma e paciente tenacidade, cheguei a convencel-os do erro, conseguindo immunizar desde maio a fins de julbo 1414 pessôs, sendo vaccinadas 396 e revaccinadas 1018, sem contar 470 inoculações praticadas nos operarios do Canal do Mangue, e cerca de 200 individuos que a pedido meu se vaccinaram no Instituto Vaccinico, ou por intermedio de medicos de sua confiança.

o povo, em geral tem aversão à remoção $p^{\underline{a}}$ hospitaes de isolamento, e esse sentimento, aliás injustificavel e filho apenas da sua ignorancia absoluta em materia de hygiene, foi um elemento por mim aproveitado para conseguir vaccinações. ...

O povo, em geral, é obediente e submisso, aceitando os conselhos e determinações da auctoridade sanitaria, que vae cumprindo sem grande difficuldade o regulamento sanitario, notando eu com satisfaçäo que as condições sanitarias melhoram sensivelmente.

Fiz desocupar e fechar para serem reconstruidas umas, e completamente reformadas outras que se achavam em pessimas condições hygienicas, duas estalagens, tres casas de commodos uma casa commercial e dois domicilios particulares. Uma das casas de commodos já foi reconstruida, sendo hoje $1 \mathrm{um}$ bom domicilio particular; uma estalagem e os seis domicilios estão em obras; as restantes estão interdictadas, aguardando licença da Prefeitura. ...

Há necessidade de fechar, para demolir, mais cinco grandes estalagens (cortiços), em más condições, e não susceptiveis de melhoramentos, e bem assim outras habitações $p^{\underline{a}}$ serem reformadas, o que irá se fazendo opportunamente.

Tenbo, porém, adiado essa providencia, diante da falta de habitações para operarios, e que, fechadas as estalagens, vae essa pobre gente peiorar as suas e as condicões geraes, aboletando-se em predios communs, transformados pela ganancia de exploradores sem 
escrupulo nas chamadas casas de commodos, verdadeiros formigueiros, onde dominam em geral a immoralidade e a porcaria, onde a promiscuidade e a agglomeração geram as molestias e a patifaria, trazendo o definhamento physico e a perversão moral d'esse povo. Enquanto os governos não enfrentarem com animo decidido o importanteproblema das habitações para operarios, n'uma capital como esta, onde é notavel a proporção d'esse grupo, a hygiene encontrará serios embaraços na debelação das epidemias e nas medidas geraes de saneamento.

Esses desgraçados vivem agora de malas às costas, escurraçados d'aqui para ali, sem encontrar habitações regulares, em numero sufficiente e de preço ao seu alcance, aboletando-se familias inteiras em cubiculos detestaveis, para serem d'ali ha pouco removidas pela auctoridade sanitaria da zona, que deseja saneal-a, para uma outra, onde por sua vez a auctoridade competente faz o mesmo, e assim em seguida.

Isso traz-lhes o desanimo, a irritação, e muitas vezes o despertar de máos instinctos, abafados pelo trabalho que encontram facilmente na epocha presente.

As medidas a tormar-se a respeito de tão tristesitılação tornam-se imprescindiveise inadiaveis, d'ellas devendo participar muito directamente a repartição da bygiene publica. ...

Nas visitas systematicas da policia sanitaria tive opportunidade de verificar que é relativamente satisfactorio o estado sanitario d'essa população. Dados os seus babitos de relaxamento, sendo relativamente limitada a porcentagem dos tuberculosos e enfraquecidos.

Acredito que melhoradas as condições hygienicas das habitações, modificados os habitos da população pelas constantes visitas, conselhos e exigencias da auctoridade sanitaria relativas ao asseio e á prophylaxia, evitando as agglomerações, e dadas providencias efficazes para o bom funccionamento dos esgotos, ao calçamento regular das ruas, a limpeza das mesmas, à regularização de valas e sargetas, etc. será o Rio de Janeiro uma cidade de primeira ordem, que causará inveja as grandes capitais pela sua salubridade e belleza natural e imponente.

Rio de Janeiro, 8 de janeiro de 1905" 


\section{CASA DE OSWALDO CRUZ}

\section{DEPARTAMENTO DE ARQUIVO E DOCUMENTAÇÃO}

\section{SETOR DE ARQUIVO INSTITUCIONAL FIOCRUZ}

\section{Fundos e seções}

Presidência

Secretaria Geral

Assessoria de Planejamento Estratégico

Diretoria de Administração Instituto Oswaldo Cruz

Direção

Divisão de Microbiologia e Imunobiologia

Depto. de Medicina Tropical Hospital Evandro Chagas Depto. de Bioquímica e Biologia Molecular Depto. de Zoologia Médica Escola Nacional de Saúde Pública Secr. de Administração Gerảl Coord. dos Cursos Descentralizados de Saúde Pública

\section{Coleções artificiais}

Coleção de história

administrativa da Fiocruz

\section{SETOR DE ARQUIVOS \\ PARTICULARES E DE OUTRAS INSTITUIÇÕES}

\section{Arquivos particulares}

Belisário Penna

Heraclides de Souza Araujo

José Dias Correia Sobrinho

Oswaldo Cruz

\section{Coleções particulares}

Álvaro Tavares de Souza

Carlos Chagas Filho

Clementino Fraga

Lauro Travassos

Miguel Osório de Almeida

Raphael de Paula Souza

Paulo de Góes

Walter Oswaldo Cruz

\section{Arquivos e coleções de outras} instituições e organismos

Arquivo histórico da Fundação Serviços de Saúde Pública

Coleção VIII Conferência Nacional de Saúde

Col. Associação Internacional de Estudos Langdorff

\section{Coleções artificiais}

Políticas prioritárias do Inamps: 1985-88

Fundação Rockefeller no Brasil
SETOR DE ICONOGRAFIA

E ÁUDIO VISUAIS

\section{Arquivo fotográfico \\ Fiocruz}

Atividades científicas

Campanhas sanitárias

Eventos

Eventos científicos

Instalações

Oswaldo Cruz: vida e obra

Personalidades

Carlos Chagas: vida e obra

Belisário Penna

Heráclides de Souza Araújo

Coleção de documentos avulsos

\section{Arquivo de imagens}

em movimento

Videos editados

Produção Fiocruz

Outras produções

Banco de imagens

\section{Arquivo sonoro}

Programas de história oral Memória de Manguinhos Memória da Previdência e Assistência Médica no Brasil Memória da Tuberculose Políticas prioritárias do Inamps: 1985-1988 
O arquivo particular do sanitarista Belisário Penna possui cerca de três metros lineares de documentos que envolvem correspondência, relatórios, produção intelectual, recortes de jornais, documentos pessoais, fotografias e permite o acompanhamento de toda a trajetória pessoal e profissional do titular. Sua vasta documentação inclui missivistas como Oswaldo Cruz, Carlos Chagas, Afrânio Peixoto, Renato Kehl, Plínio Salgado e outros; séries fotográficas de postos de profilaxia rural no Rio de Janeiro; registros diversos das campanhas públicas em que esteve envolvido, bem como de sua atuação pelo 'saneamento dos sertões'.

O acervo da Casa de Oswaldo Cruz vem sendo constituído a partir de três linhas. A primeira tem por objetivo a reunião e tratamento dos conjuntos documentais sem uso corrente acumulados pela Fiocruz e suas unidades. A segunda realiza-se através da coleta e reunião de arquivos e coleções de particulares ou de outras instituições e organismos das áreas de ciências biomédicas e saúde pública. A terceira volta-se para a constituição, a partir de programas e projetos específicos, de um acervo de depoimentos orais.

\author{
Fernando Antônio Pires Alves \\ Ricardo Augusto dos Santos \\ Wanda Suzana Hamilton \\ Casa de Oswaldo Cruz
}

\author{
Casa de Oswaldo Cruz/Fiocruz \\ Departamento de Arquivo e Documentação \\ Av. Brasil, 4.036, sala 602 - Manguinhos \\ Rio de Janeiro - RJ CEP 21040-361 \\ Tel.: (021) 590-3690 Fax: (021) 598-4437
}

Horário de consulta: 9:00 às 16:30 hs. 


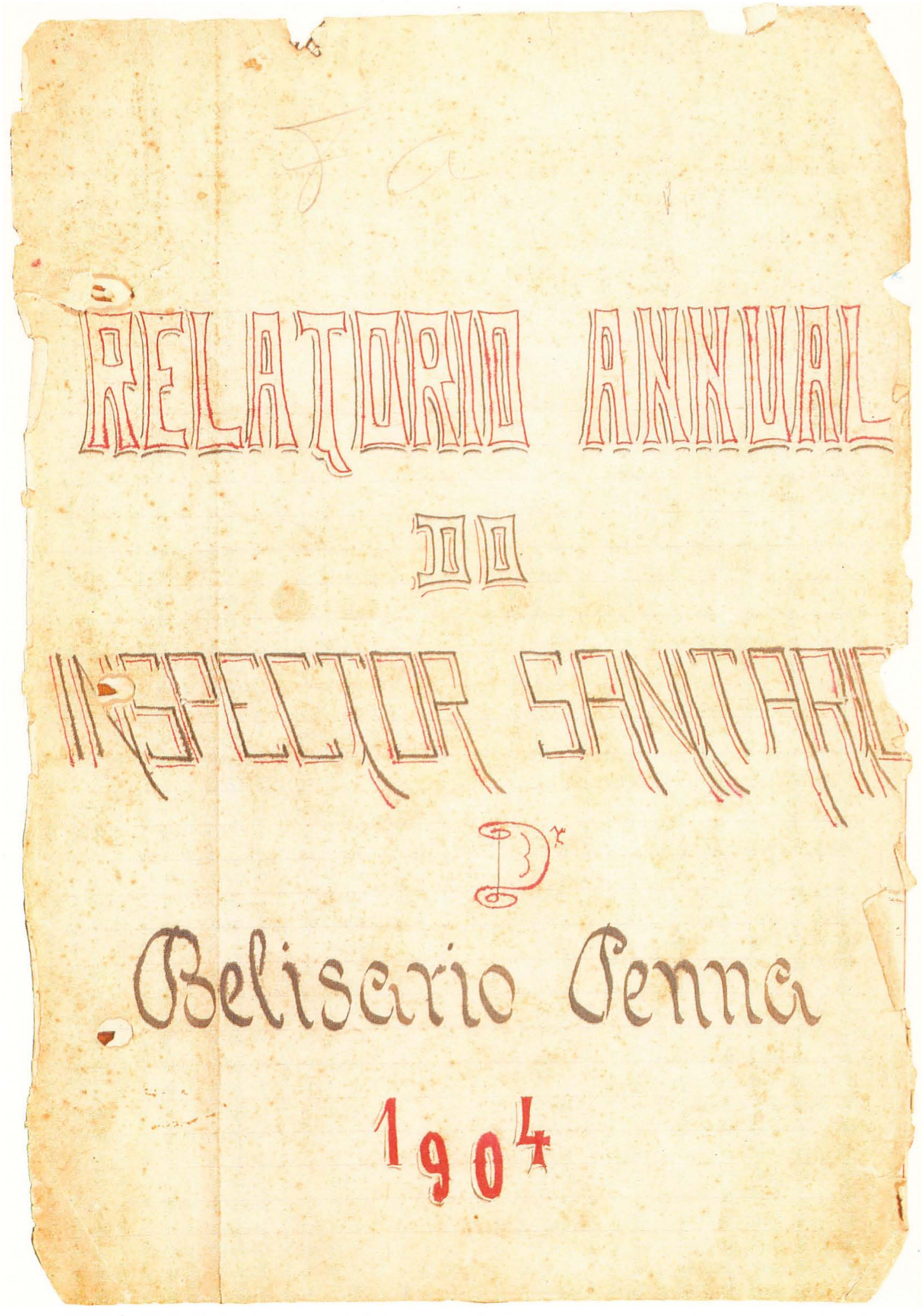

Figura 1: Folha de rosto do relatório do Inspetor Belisário Penna. 


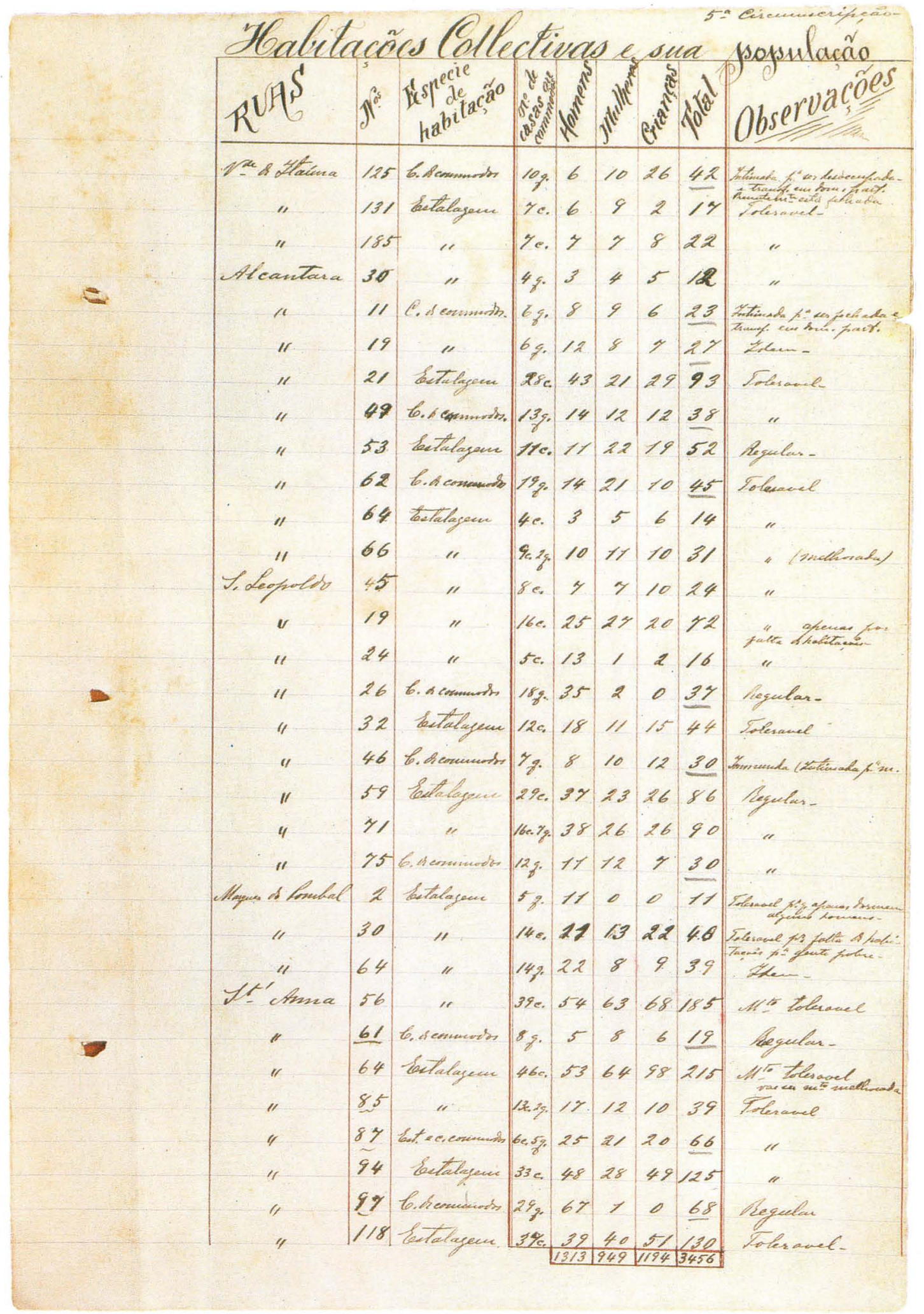

Figura 2: Quadro descritivo das habitaçōes e da populaçào residente. 